\title{
BANDEIRAS, HINOS E CANTOS: AS ARMAS CIVICAS DOS PELOTOES DE SAUDE EM SANTA CATARINA (1941-1953)
}

\author{
FLAGS, ANTHEMS AND CHANTS: HEALTH SQUADS' CIVIC WEAPONS IN SANTA \\ CATARINA (1941-1953)
}
BANDERAS, HINOS Y CANTOS: LAS ARMAS CIVICAS DE LOS PELOTONES DE SALUD EN SANTA CATARINA (1941-1953)

Michele Metelski* profissionalmichele@hotmail.com

Celso João Carminati** cjcarminati@gmail.com

\begin{abstract}
REVISTA PEDAGÓGICA
Revista do Programa de Pós-graduação em Educação da Unochapecó | ISSN 1984-1566 Universidade Comunitária da Região de Chapecó | Chapecó-SC, Brasil Como referenciar este artigo: METELSKI, M.; CARMINATI, C. J. Bandeiras, hinos e cantos: as armas cívicas dos pelotões de saúde em Santa Catarina (1941-1953). Revista Pedagógica, Chapecó, v. 19, n. 42, p. 154-170, set./dez. DOI: http://dx.doi.org/10.22196/rp.v19i42.3945
\end{abstract}

RESUMO: Apresentamos, no presente texto, os resultados de uma pesquisa histórica que se fundamentou nas relações estabelecidas entre as propostas de nacionalização do ensino e das ideias da Escola Nova, por meio de símbolos educativos que visavam à reestruturação e regeneração da pátria. Com essa perspectiva, a partir de 1940, o Estado de Santa Catarina implantou as associações auxiliares da escola, e, entre elas, os pelotões de saúde. Tomamos como pressuposto de análise o período de 1941 a 1953 e utilizamos como principais fontes de pesquisa os relatórios e as atas dessas associações, documentos escritos pelos próprios alunos alistados nos pelotões. As fontes permitem compreender como as crianças interagiam e concebiam os cuidados com a saúde, possibilitando escrutinar e inferir como era o funcionamento das instituições que objetivavam inculcar valores morais e físicos, incorporados exatamente como pretendia o discurso médico higienista.

Palavras-Chave: Pelotão de Saúde. Higiene. Civismo. Educação.

ABSTRACT: In this text we present the results of historical researches based on the established relationship among the teaching and the "New School" ideas nationalization through educational symbols that aimed the restructure and revitalization of the country. With this perspective, since 1940, Santa Catarina State implemented the Schools' Support Associations, among them the Health Squads. Thereby, based on the analysis consumption the period of time from 1941 to 1953 we used as main research sources the Reports and Agendas of those Associations which were written by the Squads 'students. Then, these ones allowed us to understand how children interacted and dealt with the health's care, so we could scrutinize and elicit how the institutions that aimed to instill moral and physical values worked, just like added in the hygienist Doctor's speech.

Keywords: Health Squad. Hygiene. Civility. Education.

RESUMEN: Presentamos, en este texto, los resultados de un estudio histórico basado en las relaciones establecidas entre las propuestas de nacionalización de la educación y las nuevas ideas escolares, a través de símbolos educativos dirigidos a la reestructuración y regeneración de la patria. Con esta perspectiva, desde 1940, el Estado de Santa Catarina implantó las asociaciones auxiliares de la escuela, y entre ellas los pelotones de salud. Tomamos como hipótesis de análisis el período de 1941 a 1953 y utilizamos como fuentes principales de investigación los informes y los actas de estas asociaciones, documentos escritos por los propios alumnos listados en los pelotones. Las fuentes les permiten entender cómo los niños interactúan y conciben el cuidado de la salud, permitiéndoles escudriñar e inferir cómo funcionaban las instituciones, que tenían como objetivo inculcar valores morales y físicos, incorporados exactamente como el discurso fue pensado. Higienista dental.

Palabras clave: Pelotón de Salud. Higiene. Civilidad. Educación. 


\begin{abstract}
* Doutoranda em Educação na Linha de Pesquisa História e Historiografia da Educação na Universidade do Estado de Santa Catarina (UDESC), Mestre em Educação na Linha de Pesquisa História e Políticas Educacionais pela Universidade Estadual de Ponta Grossa - UEPG (2013); Especialista em Bioengenharia pela Universidade Estadual do Paraná (UNESPAR); Especialista em Metodologia da Ação Docente pelo Centro Universitário de União da Vitória - UNIUV (2012); Graduada em Ciências Biológicas pela Universidade Estadual do Paraná (UNESPAR); Cursando Especialização em Metodologia do Ensino de Ciências Biológicas (UNIASSELVI); pesquisadora na área da História da Educação, Discurso Médico-higienista, História da Medicina no Brasil e Biologia Geral.

** Doutor em Educação pela Universidade Federal de Santa Catarina. Pós-Doutor pela Università Degli Studi di Bergamo - Itália e Universidade de Lisboa - Portugal. Professor do Departamento de Pedagogia e do Programa de Pós-Graduação em Educação Universidade do Esatado de Santa Catarina - UDESC. Diretor de Ensino de Graduação da FAED/UDESC.
\end{abstract}

\section{INTRODUÇÃO}

Procuramos, aqui, compreender e demonstrar como era o funcionamento da associação escolar pelotão de saúde em escolas no Estado de Santa Catarina a partir da década de 1940. Os pelotões de saúde foram instituídos pela legislação de ensino e tiveram significativa participação das crianças, dos professores e também dos pais.

Em Santa Catarina, em um momento de franca nacionalização do ensino cujas campanhas tendiam a formar e a fixar o ideal do modelo familiar brasileiro, as escolas foram chamadas a constituir esses pelotões, que foram regulamentados a partir da Circular $\mathrm{n}^{0} 26$, de 19 de março de 1941, no governo Nereu Ramos. Dentre diversas outras medidas, em um momento de tentativas de afirmação do Estado Novo, visavam ao ensino da higiene e da educação sanitária de forma ativa, realizada pelos próprios alunos, que deveriam disseminar os hábitos salutares junto aos colegas, às famílias e à população.

Destarte, procurou-se criar uma grande consciência sanitária entre a população. As crianças desempenharam papel essencial nessa cruzada higienista, pois eram verdadeiras combatentes na luta contra as doenças.

Os pelotões eram organizações hierárquicas e tinham regras de funcionamento. As crianças trabalhavam e serviam ao discurso nacionalista, cujo papel emoldurava e inculcava os valores morais e salvacionistas da pátria, com os quais se propunha, dessa forma, tirar o país do atraso em que se encontrava, reduzindo, ao mesmo tempo, a "incivilidade" da população reinante na nação.

\section{CUMPRIR COM OS DEVERES: PESSOAS DIGNAS DA PÁTRIA E DA SOCIEDADE}

Conforme explica Eggert-Steindel (2004, p. 41), “[...] a Constituição de 1937 instituiu o Estado Novo, que estimulou as unidades federativas a efetivarem a Campanha de Nacionalização". Tal projeto visava a dar nuances brasileiras às áreas colonizadas por imigrantes europeus que se haviam instalado em vários estados da Confederação; no entanto, um número mais expressivo se concentrava no sul do Brasil, ou seja, no Paraná, em Santa Catarina e no Rio Grande do Sul. Pretendia-se, com a referida campanha, levar esses imigrantes, e seus descendentes, a incorporar no seu dia a dia, em seus costumes, um ethos de nação brasileira, toda uma gama de características ditas brasileiras, mudando alguns hábitos trazidos da terra natal, que ainda se mantinham fortes em solo aquém-mar, como a língua falada e escrita. "A campanha de nacionalização no Estado Novo significou fazer o imigrante e seus descendentes esquecerem as origens estrangeiras e se abrasileirarem" (EGGERT-STEINDEL, 2004, p. 41). 
De acordo com Tambara e Arriada (2009), o início do século XX foi marcado, no Brasil, por intensa campanha de divulgação dos valores decorrentes da universalização do acesso ao sistema escolar. De certa forma, a República procurava plasmar uma identificação com a educação. Este processo estava associado a alguns valores específicos, dentre os quais se destacavam o civismo e o moralismo patriótico:

O discurso nacionalista é um exemplo disso, pois ao fundir o significado de nação com o de pátria, forçou uma homogeneização a partir de certos núcleos de adesão, realizando um movimento complementar de integração e exclusão ao descrever grupos, impor espaços, conferir a palavra ou negá-la. (KREUTZ, 1999, p. 85).

O esforço em tornar o país uma nação civilizada, educada e cortês esteve associado aos princípios e valores patrióticos. A ideia de formar patriotas foi um discurso que, no período em tela, circulou no Brasil e, consequentemente, nas escolas. A nação, afetada pela onda da escolarização em nome de um projeto de modernidade e civilidade, mobilizou diferentes contextos sociais. No período em que ocorreu a "explosão educativa" do ensino em Santa Catarina, o país se encontrava diante das iniciativas de afirmação dos Estados-nação. Era necessário difundir o ensino moral e cívico, a educação moral laica e a cruzada patriótica:

O decênio 1940/50 apresentou nítida clareza do que foi denominada "explosão educativa”. E foi, exatamente, no nível do ensino primário - que abrange a maior extensão da responsabilidade do Poder Público - onde se deu este expressivo choque de demanda pela escolarização. Em Santa Catarina, particularmente, a demanda se exaltou no meio rural que procurava se aproximar, ideológica e culturalmente, do meio urbano. (THOMÉ, 2002, p. 43).

Aos poucos, o processo de civilização foi entrando no cotidiano das pessoas e causando uma série de mudanças econômicas e sociais como o trabalho infantil, que era demasiado para o período em um país em que se pretendia igualar às grandes nações que se preocupavam com a moral e a saúde. A educação parecia transformar-se em fator de mudança social, capaz de despertar nos indivíduos o ideal de civismo, e, consequentemente, de nação, formando cidadãos aptos a conduzir o país na direção do progresso. Cabia ao ensino moldar as crianças, propondo-lhes valores de igualdade e criando bons hábitos, certamente articulados a princípios capazes de evitar fissuras internas na sociedade. Em outras palavras, a educação deveria transformá-las em indivíduos participantes e interessados no reajustamento 
1 Tomando como base a publicação do Decreto 2.991 de 28 de abril de 1944 (SANTA CATARINA, 1944a), as Associações Auxiliares da Escola se dividiam em: Liga Pró-Língua Nacional - visava ao espírito de cooperação que deveria ser implantado nas escolas, não apenas aos professores, mas aos educandos, tornando mais sólido o espírito nacional. Era uma instituição essencialmente nacionalizadora que objetivava levar para a escola a preparação de homens perfeitamente integrados no valor e grandeza de sua Pátria. Seu objetivo era formar brasileiros de corpo e alma; Biblioteca - desde o início da reorganização do ensino no Estado de Santa Catarina, as bibliotecas ocuparam um lugar de destaque nas organizações escolares. As bibliotecas escolares foram organizadas em todas as escolas, tendo como fim angariar o maior número de livros que podiam ser lidos pelos alunos. As bibliotecas escolares somente possuíam livros que fossem do alcance da inteligência infantil e que poderiam contribuir para o seu desenvolvimento cívico, moral e intelectual; Jornal Escolar - representava uma forma de comunicação entre os pais dos alunos e um meio de preservar a memória da região, sendo escrito pelos próprios alunos; Clube Agrícola - tinha como objetivo principal propagar o amor à natureza e ensinar aos sócios atividades agropecuárias nos terrenos do estabelecimento do ensino. Despertando-se a criança no amor e o carinho pela natureza, seria possível despertar na sua própria alma o patriotismo. Acreditavam que somente se poderia ter amor e apego a terra natal depois de se aprender a respeitar e amar a natureza. Com amor e interesse pela terra que lhe foi o berço, nasceria na alma da criança o verdadeiro patriotismo. Portanto, a organização do clube agrícola possibilitava todas as ideias relativas à associação da família à escola, à personalidade e liberdade do aluno, à formação de grupos de trabalhadores e à aplicação das matérias do programa escolar e, principalmente, à formação de preciosas qualidades morais. O clube agrícola seria o exemplo fiel da vida em sociedade, seu funcionamento seria uma miniatura das sociedades em que as crianças viveriam quando estivessem adultas. Nela as crianças aprenderiam suas obrigações, seus direitos, e o respeito às pessoas e coisas; Círculo de Pais e Professores - essa instituição foi a mais difícil de se legitimar nas escolas, porque os pais não compareciam. Uma boa parte dos pais achava que mandando o filho para a escola já havia cumprido o seu dever, alguns também associavam a escola a uma prisão, onde os filhos ficavam sendo vigiados durante os estudos. Mesmo com muitos empecilhos, a instituição destinava-se a incrementar a união entre os pais e os professores, na contribuição de tudo que visava ao bem-estar das crianças e ao bom funcionamento da escola; Centros de Interesse - visavam de forma particular à objetivação do programa constituindo um trabalho de cooperação, oferecendo oportunidades de explanação so- social, "mentalmente habilitadas" a realizar mudanças sociais "sem provocar confusão e desordem" (DEWEY, 1979, p. 32).

As associações auxiliares da escola ${ }^{1}$ não ficaram fora dessa cruzada de "consciência nacional". No início das reuniões dos pelotões de saúde, os alunos entoavam hinos, cantavam e declamavam poesias. Em vários momentos, também se faziam palestras que exaltavam personalidades da história brasileira e dos valores patrióticos a elas associados:

O estímulo ao patriotismo, o uso de símbolos nacionais e comemorações das datas nacionais também são pontos destacados na legislação federal. Militares que participaram da campanha deram especial atenção ao civismo como instrumento de assimilação e meio de formação de uma "consciência nacional". Nesse aspecto, a questão educacional extrapola os limites da escola para chegar à população adulta através de solenidades públicas de exaltação aos símbolos e heróis nacionais. (SEYFERTH, 1999, p. 220).

O uso de símbolos e hinos destacava-se no período da nacionalização, visto que foram criados para transmitir o sentimento de união nacional e mostrar a soberania do país. A obrigatoriedade do Hino Nacional em todos os estabelecimentos de ensino e associações com fins educativos foi objeto da Lei $\mathrm{n}^{0} 259$, de $1^{\circ}$ de outubro de 1936 (BRASIL, 1936). Os professores e diretores que descumprissem essa legislação poderiam ter suas escolas fechadas, ser presos ou expulsos das atividades públicas.

A partir da publicação da Circular no 26, em 19 de março de 1941, ficou instituído que os pelotões de saúde utilizariam uma flâmula de cor branca, portando no canto inferior a cruz vermelha e, em letras vermelhas, o dístico "Saúde, Força, Alegria" (SANTA CATARINA, 1941). A bandeira ocupava sempre um lugar privilegiado nas salas de aula e ficava à vista de todos os alunos, sendo confeccionadas por eles próprios ou pelos professores. As reuniões realizavam-se sempre próximas às bandeiras dos pelotões, que as utilizavam também como principal objeto de poder e mérito.

Tanto as bandeiras como os uniformes constituíam motivo de orgulho, pois nem todas as escolas podiam confeccioná-los devido às condições financeiras. De fato, assim encontramos registrado: "Vimos a bandeira e o uniforme que achamos muito bonito e queremos aprontá-lo até o dia 7 de setembro" (SANTA CATARINA, 1943, p. 137).

\section{MONITORES, BANDEIRAS E SIMBOLOGIAS}

Os monitores lavavam as bandeiras, passavam a ferro e as levavam limpas para serem guardadas. Algumas 
bre diversas questões de aritmética, história, botânica, geografia, higiene, linguagem etc. Esses centros eram considerados pequenos museus de classe onde se transportavam do museu geral objetos para essas sala que se ministraria as aulas práticas; Liga da Bondade - apresentava muitas dificuldades no seu processo de fundação por ter um fundo puramente psicológico. $\mathrm{O}$ próprio nome se assemelhava a algo transcendental. A organização da Liga da Bondade tinha como escopo levantar a moral dos alunos com base no princípio da modificação da prática dos bons hábitos, transformando gradativamente os pequenos costumes em virtudes permanentes; Clube de Leitura - tinha o intuito de desenvolver o gosto pela boa leitura e, ao mesmo tempo, oferecer as crianças uma poderosa fonte para sua cultura $e$ desenvolvimento social. Destinavam-se aos alunos dos estabelecimentos que já possuíam certa compreensão de leitura; Pelotão de Saúde - tinha a finalidade de inculcar hábitos e orientar a criança na aquisição de conhecimentos práticos, fornecendo-lhe um cabedal de costumes favoráveis à saúde, pelo exemplo e pelo ensino. escolas possuíam até duas bandeiras, que, em geral, mediam 60 x $40 \mathrm{~cm}$, uma para o uso em festas e outra, para o uso cotidiano.

Nas ocasiões cívicas e nos desfiles, os alunos e membros destacavam-se pelos distintivos que usavam no braço e pelas flâmulas. Talvez por esses cuidados, imprescindíveis a um elogio ou premiação, "os monitores do Pelotão de Saúde foram elogiados pela Sra. Diretora, pelo garbo com que marcharam na parada de 7 de setembro" (SANTA CATARINA, 1944, p. 195).

A simbologia do uso da cruz vermelha utilizada nas flâmulas apoiou-se na iniciativa do jovem suíço Jean-Henry Dunant (1828-1910), que ajudou os soldados feridos na batalha de Solferino, Genebra, em 1859. Depois disso, ele criou, junto a vários líderes políticos, medidas de proteção às vítimas de guerra, tendo fundado, em 1863, o Comitê Internacional da Cruz Vermelha. Suas principais ideias consistiam em criar um tratado que obrigasse os exércitos a cuidarem dos soldados feridos e as sociedades nacionais a ajudarem os serviços militares de saúde.

Seguindo esse exemplo, a Cruz Vermelha Brasileira foi fundada em 5 de dezembro de 1908, tornando-se, desde então, instituição modelar, tanto em tempos de guerra, no socorro aos feridos em campos de batalha ou na liberação de prisioneiros de guerra da forma prevista nas convenções de Genebra, como em tempos de paz, levando ajuda às vítimas de catástrofes e desastres naturais (secas, enchentes, terremotos etc.). Seu primeiro presidente foi o Dr. Oswaldo Cruz, médico e patrono da Saúde Pública no Brasil, que foi responsável pelas principais campanhas sanitaristas do início do século XX no Rio de Janeiro.

A presença da cruz vermelha estampada nos uniformes dos pelotões de saúde difundidos nas escolas catarinenses espelhava os princípios da associação Cruz Vermelha e representava, nas escolas, as pessoas encarregadas pelo trabalho sanitário, tidas como legítimas representantes de um exército. $\mathrm{O}$ distintivo, portado no braço à moda dos enfermeiros durante suas missões em guerra, igualava os membros dos pelotões a esses profissionais.

A orientação geral dos pelotões de saúde determinava o seguinte uniforme para a seção feminina: avental branco, cruz vermelha no braço esquerdo e "bibi" branco com a cruz vermelha. A seção masculina deveria usar calça comprida branca, camisa de mesma cor e cruz vermelha no braço esquerdo. Todos deveriam utilizar um "bibi" (tênis branco), também bordado com uma cruz vermelha. O uso do uniforme era obrigatório e rigoroso, a ponto de, se o aluno não o vestisse ou não pudesse ter seu próprio, ser imediatamente afastado do pelotão ao qual pertencia.

Mais tarde, em 29 de abril de 1944, o governador Nereu Ramos, pelo Decreto ${ }^{0}{ }^{2} .991$ (SANTA CATARINA, 1944a), instituiu as associações auxiliares da escola nos estabelecimentos estaduais, municipais e particulares. Nesse decreto, substitui-se a cruz vermelha original, de quatro 
pontas, pela cruz vermelha de malta, como se pode ver na imagem abaixo.
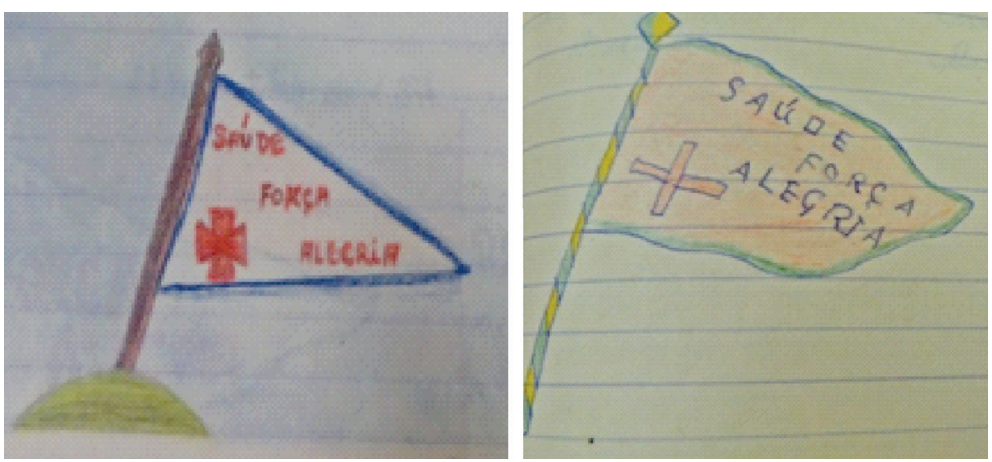

Figura 1 - Cruz de malta com oito pontas (1944) e a primeira cruz utilizada com quatro pontas (1941)

Fonte: Santa Catarina (1941, 1944).

A partir da modificação da cruz vermelha, entendemos que a finalidade dos pelotões de saúde passou a ser de verdadeiras cruzadas. A cruz de malta representa o símbolo das cruzadas, especificamente dos cavaleiros hospitaleiros, ou templários, que, a exemplo das ações medievais, conduziam seus exércitos às missões contra os inimigos, em geral os árabes que haviam ocupado a península ibérica, tendo-se iniciado o período de restauração cristã com o rei das Astúrias, Pelágio, no século VIII.

Na bandeira, a cruz de malta com oito pontas é representada pelo símbolo guerreiro dos cristãos e traz a inscrição com os deveres dos cavaleiros: amor, arrependimento, fé, humildade, misericórdia, resistência, sinceridade e verdade.

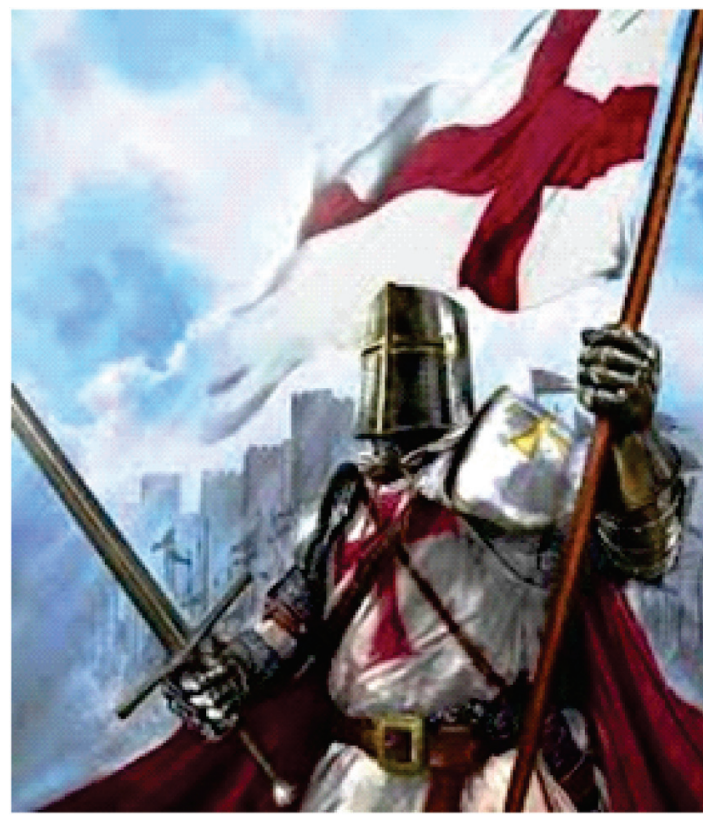

Figura 2 - Cavaleiro Templário da Idade Média segurando a bandeira com a Cruz de Malta (Baussan, estandartes de guerra)

Fonte: Childress ([s. d.]). 
Esse ideário, que envolve a cruz de malta e sua utilização simbólica nas bandeiras e uniformes dos pelotões de saúde, surge da medicina. No ocidente, a posição de maestria do médico se baseava em um personagem heroico. Para Jean Clavreul, o médico era um cavaleiro da ciência e do dever, e sinais indiscutíveis testemunham a autoridade e a sua importância, uma vez que:

Seus títulos lhe permitem falar alto, como o caduceu de seu carro lhe assegura quase uma impunidade perante a polícia. Sua sala de espera sempre cheia prova que ele é muito solicitado e sobrecarregado. O público, enquanto espera discute, fala "dele", e assim se constitui um estado de sugestibilidade favorável ao seu prestígio e sua autoridade. (CLAVREUL, 1978, p. 45).

Autoridade era a palavra que representava o discurso salvacionista dos médicos. Sua principal função era a produção sistemática de um discurso que desautorizasse todos os saberes que não fossem produzidos no âmbito da ciência e no poder da razão científica. É nesse entendimento que Keila Carvalho (2015) chega ao abordar, em seu livro A saúde pelo progresso: A regulamentação do trabalho médico no Governo Vargas (Minas Gerais - 1930-1940), a preocupação dos médicos em ampliar a percepção social sobre o ofício que desempenham, fazendo-se reconhecer não apenas sob o viés de uma elite político-econômica, mas, principalmente, como sujeitos revestidos de uma "autoridade" científica. Segundo Cunha e Magaldi (2010) Fora muito comum, nesse período e nas décadas anteriores ao Estado Novo, promover as campanhas que tivessem como base os manuais de civilidade enquanto formuladores de etiquetas e orientações às mães e às famílias, em parceria entre "médico-mulher, e as receitas de saúde e higiene para o lar".

Assim se expressam as autoras:

O cultivo das práticas de civilidade, por exemplo, deveria ser dirigido a todos, e pode estar aí uma das razões para sua presença ter se estendido das casas das famílias abastadas para as escolas, seja como materiais utilizados nas aulas, seja como produção de professores ou, ainda, como leituras feitas pelos professores e aconselhadas/prescritas aos seus alunos. (CUNHA; MAGALDI, 2010, p. 172).

Não é de se estranhar, por exemplo, que no mesmo período em que se discutia sobre os pelotões de saúde, a área da educação ainda estivesse subordinada à saúde, inclusive em nível de organização governamental. Enquanto prática escolar, a cruz de malta foi utilizada em condecorações escolares, totalmente em conformidade com o trabalho exercido pelos pelotões de saúde e pelo recebimento 
da bandeira como prêmio quando as turmas eram as mais limpas e asseadas. Para os alunos e as turmas, cuidar das bandeiras dos pelotões de saúde representava uma honra para a classe.

Ainda para nos auxiliar na compreensão dos termos adotados, pelotão, segundo o dicionário da língua portuguesa, significa divisão de uma companhia de soldados, grupo de pessoas que estão juntas. A definição de cruzada remete à expedição cristã, tal como se constituiu na Idade Média, para expulsar os muçulmanos da Terra Santa. A expressão cruzada higiênica ou sanitária foi muito utilizada por médicos e políticos para definir a luta travada pela saúde no Brasil:

Os Pais, os Educadores e os Médicos, no Lar, nas Instituições Educativo-Assistenciais, ou ondequerque seencontrem, devem manter-se unidos na luta contra as moléstias infecto-contagiosas [sic] e parasitárias. Como "cruzados" de causa santa, aos quais cumpre banir, não somente os males físicos, mas também todos os males que procuram corromper e rebaixar o espírito e a moral da humanidade. Não devem e não podem vacilar. (REIS, 1950, p. 113).

Carregar um estandarte de guerra ou uma bandeira sempre foi motivo de orgulho para qualquer tropa. O significado de honra estava ligado ao respeitoso fato de garantir que a bandeira não fosse tomada pelo inimigo em cruzadas ou missões. Perder a bandeira significava um fato desonroso, humilhante, infligido aos perdedores. Erguer e guardar uma bandeira significava a reputação do indivíduo e a unidade à qual ele pertencia. "Nos desfiles dos alunos, os membros da diretoria são destacados com sua flâmula e distintivo" (SANTA CATARINA, 1944).

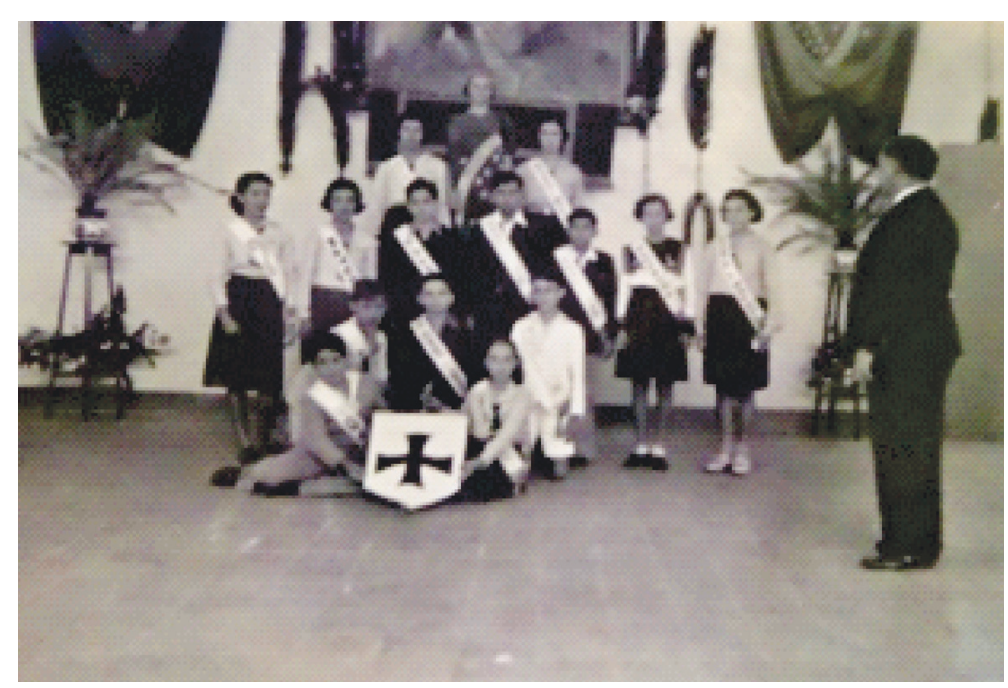

Figura 3 - Membros do pelotão de saúde do Grupo Escolar Dias Coelho exibindo a bandeira

Fonte: Santa Catarina (1944). 
As bandeiras dos pelotões de saúde eram utilizadas como troféus de limpeza e tornavam as turmas especiais e exemplares, dando-lhes status e honra, como a que foi definida pelo governo: "Será entregue a Bandeira do Pelotão à classe que tiver mais asseio e ordem" (SANTA CATARINA, 1944, p. 85). Em sinal de respeito, as crianças também prestavam continência às bandeiras. "Os bons alunos vão direito no caminho; quando vemos a bandeira, fazemos continência e tiramos o chapéu. Alunos malcriados, que fazem a continência e zombam dos outros, mais tarde serão castigados (SANTA CATARINA, 1947, p. 314).

Como muitas escolas não tinham condições de comprar os tecidos para confeccionar as bandeiras e os uniformes, recorriam a rifas e campanhas, porque as classes mais bem uniformizadas também recebiam a bandeira. A bandeira de seda com o bordado custava, à época da fonte citada, aproximadamente $\mathrm{Cr} \$$ 75,00: "Foi combinada a campanha da arrecadação de medicamentos para o Pelotão de Saúde. A classe que mais conseguir terá a honra de permanecer com a bandeira do Pelotão de Saúde na sala de aula durante uma semana" (SANTA CATARINA, 1945, p. 185).

O uniforme era indispensável nas ocasiões cívicas e deveria ser impecável. Em algumas escolas, os alunos que não o tivessem eram multados, sobretudo nas cerimônias de desfile nas quais estava prevista a visita de autoridades: "Recomendo, ainda, a preparação dos uniformes para o desfile do próximo sábado, quando estiver de visita na nossa cidade o Exmo. Sr. Dr. Aderbal Ramos da Silva, nosso governador" (SANTA CATARINA, 1948, p. 85).

As bandeiras que levavam o lema dos pelotões de saúde - "Saúde, Força, Alegria" - representavam a importância da criação de filhos fortes para servir à nação. Sem saúde não se poderiam estabelecer homens fortes para o trabalho; sem saúde e trabalho, não poderia haver alegria. Nesse sentido, legitimava-se a importância das campanhas nas escolas sobre a higiene e educação sanitária, tendo em vista que não era vantagem para o Estado ter pessoas doentes e fracas, "[...] porque o valor do Estado depende da capacidade intelectual, moral e física de cada habitante do solo" (ANGELIS, 1997, p. 442).

O lema "Saúde, Força, Alegria" foi embasado nos preceitos higienistas e eugenistas de Renato Kehl, escritor do primeiro livro sobre higiene no Brasil, na década de 1920, intitulado A Fada Higya. Este livro circulou nas escolas primárias brasileiras, disseminando os conselhos realizados por uma fada. No final, há uma referência à saúde e à alegria, que diz:

Reparta o tempo entre os estudos e os divertimentos. O homem de caráter sólido não conhece a preguiça e tem horror à indolência. O trabalho é o estímulo indispensável ao organismo, condição, mesmo da sua existência. Agir é viver; o trabalho entretém a vida. 
A ociosidade a amortece. O homem que trabalha é útil a si próprio e aos outros; o preguiçoso é prejudicial a si mesmo, e inútil e pernicioso à sociedade. (KEHL, 1930, p. 153).

Acompanhando as orientações ditadas por Gustavo Capanema, então ministro da Educação (entre 1934 e 1945), chegaram às escolas as campanhas do ideário nacionalista, cujo papel formativo era estratégico e objetivava tornar as crianças potenciais cidadãos para o projeto de modernização do país. Os hinos e as canções cívico-patrióticas estiveram presentes em todo o período estudado nesta pesquisa, além de outros períodos da história, ora com maior, ora com menor expressão. A música tinha exatamente a função de despertar o sentimento patriótico nas crianças, pois, conforme afirmava Roger Chartier (1990), as canções estão carregadas de significados e representações da realidade.

No início ou nos finais das reuniões dos pelotões de saúde, entoavam-se hinos e em algumas ocasiões também ocorriam declamações de poesias e cantos. A maioria dos hinos tinha cunho patriótico e a preferência era que se cantasse um hino diferente por dia. Entre eles, estavam: "A casa paterna a pátria"; "Salve portanto a bandeira"; "Antigamente eu ouvia"; "Poesia o passeio"; "Fui apanhar uma rosa"; "Os vícios"; "A mãe”; "A boneca"; "Tertuliano"; "A avó"; "Os tamanquinhos"; "Ao cair as folhas"; "Enfermeira"; "O passarinho"; "A borboleta"; "O tatu" (CHARTIER, 1990).

O canto do Hino Nacional e o hasteamento da bandeira tornaram-se obrigatórios nas escolas. Esses símbolos eram usados como instrumentos de controle político e ideológico:

Hino é a composição poética e musical em honra de algum fato histórico ou acontecimento. Assim, temos hinos em honra de heróis de um partido, de um clube, ainda mais, em honra de uma nação. Focalizando dessa maneira, entendemos que o hino, em sua tessitura, diz da história e dos fatos da nação, sendo, portanto, a voz que proclama suas características, quer por seus feitos e glórias, quer por suas peculiaridades geopolítico-sociais e históricas. O Hino Nacional Brasileiro está realmente dentro desta concepção. (LACOMBE; CALMON, 1989, p. 26).

No início do século XX difundia-se em Santa Catarina, o consenso estabelecido entre o poder político e as Forças Armadas sobre o necessário trabalho educativo a ser levado a cabo, que era uma tarefa de educação moral e cívica que via na obrigatoriedade da língua portuguesa, na divulgação de preceitos de higiene, da disciplina do corpo, na implantação de associações escolares e nos cantos cívicos as alternativas mais plausíveis de construção de um "espírito nacional". Apostava-se em uma mudança 
2 Durante o Estado Novo e a Segunda Guerra Mundial, as enfermeiras foram mobilizadas e responderam ocupando um lugar importante na constituição da política, na qual o ato de "servir" ao outro foi associado a servir à pátria em uma política que permitiu consolidar o front interno e impor um regime de mobilização e subordinação da sociedade ao Estado Novo, fazendo convergir políticas de saúde e saneamento com políticas de militarização e enquadramento forçado da população (CYTRYNOWICZ, 2000). “civilizadora" no comportamento, controlada e gerida pela escola, forjada pelo Estado e baseada na construção de uma "segunda natureza", altamente regulada por dispositivos disciplinares e controle (BOMBASSARO, 2012, p. 8).

Os hinos entoados pelos pelotões de saúde foram: Hino à bandeira nacional; Hino terra natal; Hino à mocidade brasileira; Hino ao Brasil; Hino às flores; Hino para a escola; Hino V de vitória; Hino descobrimento do Brasil; Hino da alvorada; Hino da liberdade; Hino luar do sertão; Hino de louvor; Hino Nacional; Hino descendentes do Brasil; Hino rufai tambores; Hino terra natal, entre outros (BOMBASSARO, 2012).

Entre todos os hinos nacionalistas mencionados, chamou-nos a atenção o "Hino dos enfermeiros", dando evidência ao papel desses referenciais da saúde nas escolas, nas campanhas higienistas e sanitaristas. Por seu papel de atenção, de piedade voltada ao bem-estar das crianças, em muitas escolas as monitoras dos pelotões de saúde eram chamadas de enfermeiras, ou samaritanas, expressão religiosa que vem das iniciativas cristãs femininas que atendiam os doentes. Aliás, este é um movimento ainda hoje presente em escolas e hospitais confessionais católicos.

Em conformidade com Cytrynowicz (2000), a utilização da enfermagem e das enfermeiras como profissão-modelo para preparar mulheres para servir à sociedade e ao Estado teve apelo junto às classes médias. A profissão de enfermeira constituía um importante canal de afirmação social e profissional para as mulheres dos estratos médios da população a partir do final dos anos 1920 e, especialmente, nas décadas de 1930 e 1940. A carreira de enfermeira $^{2}$, junto à de professora primária, era uma das opções possíveis, desde o século passado, para moças destes estratos sociais. As funções das monitoras igualavam-se às das enfermeiras, pois as noções de enfermagem eram dadas às meninas na escola e visavam a cooperar com a defesa nacional, com amor e cunho patriótico. O Estado Novo tornou a profissão de enfermeira uma aliada de sua meta nacional. Abaixo, lê-se, na letra do hino de Erico Cramer, o apelo para que o Brasil ouvisse a voz das samaritanas.

Assim como os hinos, as canções também faziam parte das medidas nacionalistas no pós-Primeira Guerra Mundial e exigiam transformações nas escolas, principalmente por causa dos imigrantes (italianos, alemães, austríacos etc.). Para essas mudanças, exigia-se que os professores fossem brasileiros natos e falassem a língua pátria. Os currículos escolares precisavam incluir noções de civismo, cantos e hinos patrióticos. 


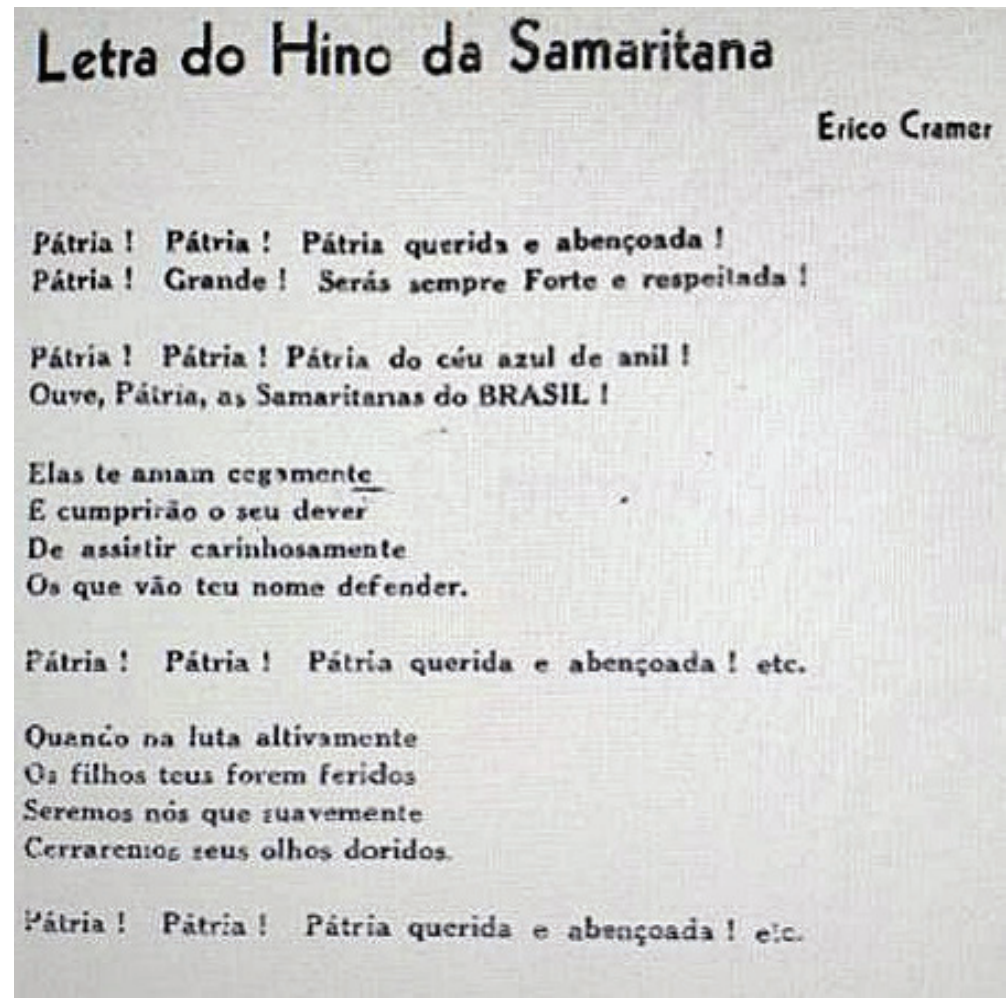

Figura 4 - Hino da Samaritana escrito por Erico Cramer Fonte: Revista da Cruz Vermelha Brasileira (1944).

Assim, pela via da música, também se tinha por objetivo formar o cidadão, uma vez que a afirmação de uma nação era uma das bandeiras do governo de Getúlio Vargas. A música representava uma ferramenta importante para a unificação artística, política e musical. Entre as canções, destacamos: canção sou brasileiro; canção estudantes do Brasil; canção do soldado; canto à escola; canto saberemos lutar; canto da escola complementar; canção terra brasileira; canção ao pescador; canção terra virgem; canção em forma vamos contentes; canção damas da cruz; canção sabes tu qual é a terra; canção avante camaradas; canção Deus salve a América; canção que nuvem mimosa; canção a gaúcha; canção a barquinha; canção terras feiticeiras; canção os passarinhos; canção brasileiros jovens fortes; canção Brasil amai as árvores; canção pega passarinho; canção matinal; canção o marimbondo; canção a volta da primavera; canção salve aurora; canção Brasil; canção o sapo; canção o marinheiro.

\section{CONSIDERAÇÕES FINAIS}

A música possuía uma grande capacidade pedagógica e educativa no novo Estado nacional, cujo principal objetivo era realizar a tarefa de promover o civismo e a disciplina coletiva, a disciplina do corpo, das almas e dos pensamentos, com a finalidade de formatar uma ideologia nacionalista. 
3 Os trechos da obra de Fontenelle (1930) foram citados sem correções.
Dessa maneira, os patronos dos pelotões de saúde eram escolhidos pelos monitores para representar as associações e se utilizavam de símbolos como bandeiras, hinos e canções de civismo. Os patronos, do latim patronus, eram figuras consideradas heroicas, que defendiam uma causa. Alguns eram regionais, como o educador Elpídio Barbosa, Nereu Ramos, Irineu Busnardo, mas, na maioria das vezes, eram nacionais e representavam títulos honrosos.

Alguns médicos foram nomeados como patronos dos pelotões de saúde. Entre eles, estavam: Carlos Chagas, Abdon Batista, Pedro Ferreira e Silva, Claudio Luiz da Costa, Laurindo Rabelo, Belisário Pena e Osvaldo Cruz, tendo sido este o que mais foi homenageado. Acredita-se que a escolha do nome de Osvaldo Cruz para patrono nos pelotões de saúde ocorreu principalmente devido à sua contribuição para pesquisas e campanhas de saúde dos brasileiros. Pioneiro nos estudos das moléstias tropicais, Osvaldo Cruz foi um médico que se dedicou aos estudos epidemiológicos, bacteriológicos e sanitários no Brasil. Atuou principalmente na erradicação da febre amarela no Rio de Janeiro implantando vacinas e intensificando o valor sanitário, alcançando assim o progresso que se almejava. "O progresso do Brasil teria sido impedido, si Oswaldo Cruz não tivesse extinguido a endemia de febre amarela na capital do paiz e traçado o programma do seu exterminio em todo o Brasil" (FONTENELLE, 1930, p. 5) . $^{3}$

A vida dos patronos era abordada nas reuniões dos pelotões de saúde, durante as quais se exaltavam os feitos realizados por eles. Entre os patronos nomeados havia médicos, figuras políticas, poetas, estadistas, escritores, advogados, prefeitos, militares, sacerdotes, professores, imperadores etc.

$\mathrm{Na}$ ata de reunião do Grupo Escolar Olívio Amorim, o monitor escreve: "A professora explicava a vida do patrono e depois as crianças faziam trabalhos para publicar no jornalzinho da escola; faziam uma biografia do patrono com o fim de ser aproveitada a melhor para o jornal do grupo escolar (SANTA CATARINA, 1943).

As associações escolares atuavam além da formação escolar, instruindo os sujeitos a uma autonomia voltada para o trabalho e a configuração de um ethos brasileiro que se almejava construir naquele momento em prol da Campanha de Nacionalização. 


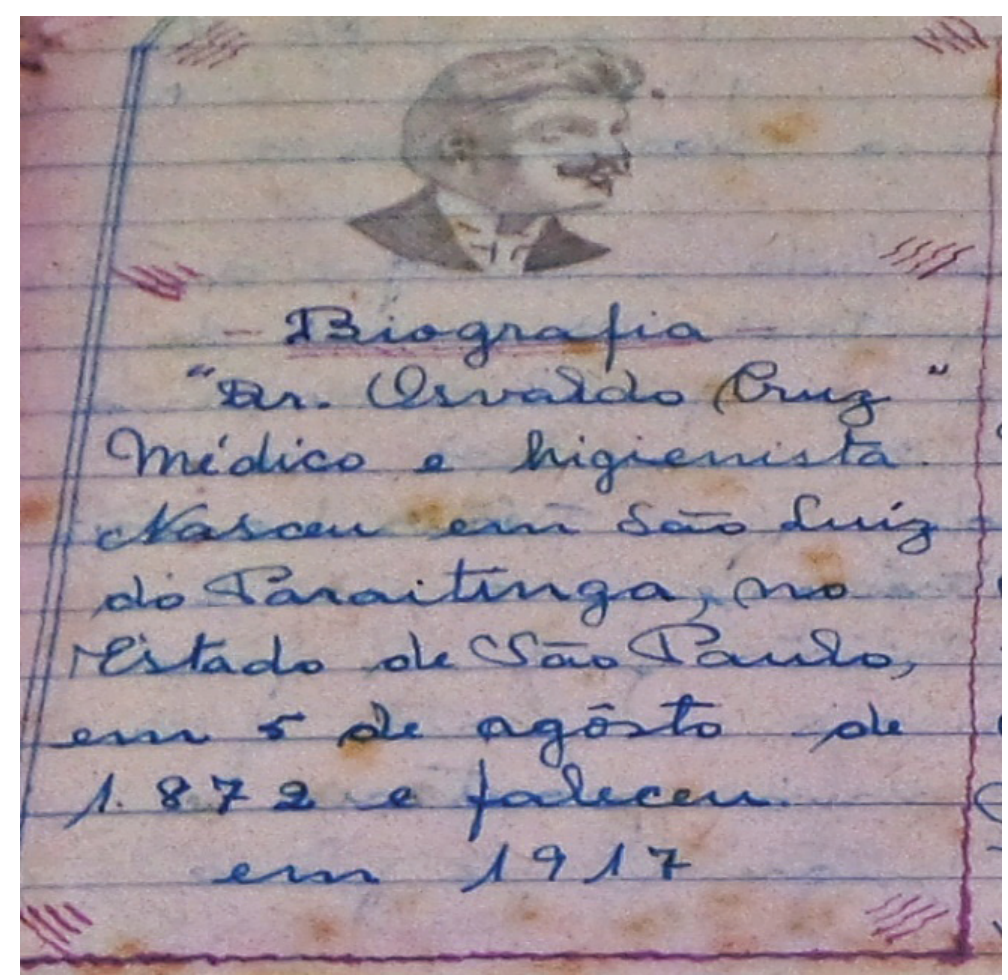

Figura 5 - Biografia do pelotão de saúde Dr. Osvaldo Cruz no Grupo Escolar Almirante Boiteux (1948)

Fonte: Santa Catarina (1948).

Para Prates, Oliveira e Teive (2012), as associações escolares foram práticas idealizadas com a finalidade de dar um novo significado à escola primária. Foram colocadas em prática nos ambientes escolares e não figuraram exclusivamente nas determinações curriculares do Estado, a fim de proporcionar aos educandos o ensejo de praticar ações sociais, com o intuito de torná-los responsáveis e colaboradores. Deste modo, Cunha (2010, p. 14) nos leva a considerar que:

As práticas escolares desenvolvidas no âmbito dessas associações como um produto das exortações cívicas, de cunho nacionalista para promover o revigoramento do amor pátrio em razão da participação, considerada vitoriosa, do Brasil na Segunda Guerra, e pode-se constatar que tais iniciativas constituam o cerne dos projetos políticos do Estado traçados especialmente para a educação e cultura.

Naquele momento, eram recorrentes as apostas de governos na organização da instrução e na educação em matéria de saúde e higiene, articuladas com as gestões e administrações de cidades e países, principalmente por meio de repartições sanitárias, ou de saúde pública, com a colaboração de outras repartições oficiais, "[...] como instrucção, obras etc., ou organizações particulares e semi-particulares, como a Cruz Vermelha, Ligas, Associações (FONTENELLE, 1930). 
Os pelotões de saúde representavam um trabalho em prol da saúde, que se acreditava, cada vez mais, constituir um meio de criar bons hábitos. A formação de hábitos sadios repousava na prática ensinada às crianças e no exemplo da professora, a qual as estimulava pela imitação, pelas recompensas, pelos jogos, pelas representações, pelos pelotões de saúde e pelos torneios. Assim, as crianças ganhavam pontos em um torneio que garantiria saúde, força e alegria, uma vez que a ideia principal se fundamentava na associação da saúde com a alegria.

Se, nos manuais de civilidade, a influência das famílias sobre as crianças era o que delimitava uma formação de boas maneiras, nas campanhas escolares, fomentadas por agentes externos, como os que aqui foram apresentados, dos pelotões de saúde, tiveram por alvo alcançar primeiramente as crianças e, a partir destas, as famílias e a sociedade. Os hábitos difundidos nos pelotões reforçavam a necessidade de formação do caráter de bons cidadãos, herdeiros da tradição, resultantes de uma rede de forças que tinham por base incutir valores capazes de impulsionar sociabilidades. Se, a partir do que escreve Le Goff (1984), por um lado, os arquivos mostram a força de um documento por sua monumental consistência; por outro, ao ouvir as fontes e ao dialogar com elas, pode-se escrutinar, por suas problematizações, o que revelam por sua condição de testemunhos de um passado, cujos indícios permitem reinterpretar e escrever a história das associações dos pelotões de saúde sob os traços da vida social de então.

\section{REFERÊNCIAS}

ANGELIS, Nicolau Meira de. Pela perfeição da raça brasileira. In: COSTA, Maria José Franco Ferreira da et al. (Org.). I Conferência Nacional de Educação: Curitiba, 1927. Brasília: INEP, 1997. p. 437-445.

BOMBASSARO, Ticiane. A educação Física no Estado de Santa Catarina: a construção de uma pedagogia racional e científica (1930-1940): fragmentos para uma história da educação do corpo em Santa Catarina. Florianópolis: DIOESC, 2012.

BRASIL. Lei $\mathrm{n}^{\circ}$ 259, de $1^{\circ}$ de outubro de 1936. Torna obrigatória, em todo o país, nos estabelecimentos de ensino e associações de fins educativos, o canto do Hino Nacional. 1936. Disponível em: <http://www2.camara.leg.br/legin/ fed/lei/1930-1939/lei-259-1-outubro-1936-556512-publicacaooriginal-76565-pl.html>. Acesso em: 3 nov. 2017.

CARVALHO, Keila. A saúde pelo progresso: a regulamentação do trabalho médico no governo Vargas (Minas Gerais - 1930-1940). Rio de Janeiro: Amaultifoco, 2015. 
CHARTIER, Roger. A história cultural: entre práticas e representações. Lisboa: DIFEL, 1990.

CHILDRESS, David Hatcher. The Knights Templar. ([s. d.]). Disponível em: <http://greyfalcon.us/The\%20 Knights\%20Templar.htm>. Acesso em: 10 nov. 2017.

CLAVREUL, Jean. A ordem médica, poder e impotência do discurso médico. Rio de Janeiro: Brasiliense, 1978.

CYTRYNOWICZ, Roney. A serviço da pátria: a mobilização das enfermeiras no Brasil durante a Segunda Guerra Mundial. Hist. Cienc. Saúde - Manguinhos, Rio de Janeiro, v. 7, n. 1, p. 73-91, mar./jun. 2000.

CUNHA, Maria Teresa Santos. Civilidade em textos: estudo sobre um jornal manuscrito infantil (1945-1957). Florianópolis: FAED/UDESC, 2010.

CUNHA, Maria Teresa Santos; MAGALDI, Ana Maria B. de Melo. Lições para mães e família: um estudo sobre manuais educativos na sociedade brasileira entre fins do século XIX e as primeiras décadas do século XX. In: MENDONÇA, Ana Waleska (Org.). História e Educação. Dialogando com as fontes. Rio de Janeiro: Editora Forma \& Ação, 2010.

DEWEY, John. Democracia e educação. 4. ed. São Paulo: Companhia Editora Nacional, 1979.

EGGERT-STEINDEL, Gisela. Dos espaços de leitura à constituição da instituição de leitura pública conformação da biblioteca municipal de Jaraguá do Sul (SC): discursos e percursos (1937-1983). 2004. 213 f. Tese (Doutorado em Educação) - Programa de Pós-Graduação em Educação, Universidade de São Paulo, São Paulo, 2004.

FONTENELle, José Paranhos. Compêndio de Hygiene. Rio de Janeiro: [s. n.], 1930.

KEHL, Renato. A Fada Higya. São Paulo: Livraria Editora Francisco Alves, 1930.

KREUTZ, Luiz. Identidade étnica e processo escolar. Cadernos de Pesquisa, São Paulo, n. 107, p.79-96, jul.1999.

LACOMBE, Américo Jacobina; CALMON, Pedro. Presidentes da República, símbolos, hinos e canções. Brasília: CEDIL/ALHAMBRA/MEC/FAE, 1989.

LE GOFF, J. Documento/Monumento. In: ENCICLOPÉDIA EINAUDI. Memória - História. Lisboa: Imprensa Nacional - Casa da Moeda, 1984. p. 11-50. 
PRATES, Fernanda Ramos Oliveira; OLIVEIRA, Julia Vieira Tocchetto de; TEIVE, Gladys Mary Ghizoni. Associações auxiliares da escola: vestígios de sua incorporação à cultura dos grupos escolares Lauro Müller e Alberto Torres (1946 e 1956). In: SEMINÁRIO DE PESQUISA EM EDUCAÇÃO DA REGIÃO SUL, 9., 2012, Caxias do Sul. Anais... Caxias do Sul: Universidade de Caxias do Sul, 2012. 1 CD-ROM.

REIS, João de Deus Bueno. A medicina a serviço da educação. São Paulo: Livraria Vademecum, 1950.

REVISTA DA CRUZ VERMELHA BRASILEIRA. São Paulo: [s. n.], 1944.

SANTA CATARINA. Circular $\mathbf{n}^{0} \mathbf{2 6}$, de 19 de março de 1941. Florianópolis: APESC, 1941.

SANTA CATARINA. Relatório Anual dos Pelotões de Saúde, 1942. Florianópolis, APESC, 1942.

SANTA CATARINA. Relatório Anual dos Pelotões de Saúde, 1943. Florianópolis: APESC, 1943.

SANTA CATARINA. Decreto $\mathbf{n}^{\circ} \mathbf{2 . 9 9 1}$, de 29 de abril de 1944. Florianópolis: APESC, 1944a.

SANTA CATARINA. Relatório Anual dos Pelotões de Saúde, 1944. Florianópolis: APESC. 1944b.

SANTA CATARINA. Relatório Anual dos Pelotões de Saúde, 1945. Florianópolis: APESC, 1945.

SANTA CATARINA. Relatório Anual dos Pelotões de Saúde, 1947. Florianópolis: APESC, 1947.

SANTA CATARINA. Relatório Anual dos Pelotões de Saúde, 1948. Florianópolis: APESC, 1948.

SEYFERTH, Giralda. Os imigrantes e a campanha de nacionalização do Estado Novo. In: PANDOLFI, Dulce (Org.). Repensando o Estado Novo. Rio de Janeiro: Ed. FGV, 1999. p. 199-228.

TAMBARA, Elomar; ARRIADA Eduardo. Civismo e educação na primeira república - João Simões Lopes Neto. História da Educação, Pelotas, v. 13, n. 27, p. 279-292, jan./ abr. 2009.

THOMÉ, Nilson. Primeira História da Educação Escolar na Região do Contestado. Caçador: UNC/Museu do Contestado, 2002. 